\title{
Synergistic interaction of eugenol and antimicrobial drugs in eradication of single and mixed biofilms of Candida albicans and Streptococcus mutans
}

Huma Jafri ${ }^{1 *}$, Gopa Banerjee ${ }^{2}$, Mohd Sajjad Ahmad Khan ${ }^{3}$, Iqbal Ahmad', Hussein Hasan Abulreesh ${ }^{4}$ and Abdullah Safar Althubiani ${ }^{4}$

\begin{abstract}
In vitro eradication of the C. albicans and S. mutans mixed biofilms by eugenol alone and in combination with the antimicrobial drugs. Previously characterized strains of C. albicans (CAJ-01 and CAJ-12) and S. mutans MTCC497 were used to evaluate the eradication of biofilms using XTT reduction assay, viability assay, time dependent killing assay and scanning electron microscopy (SEM). Synergistic interaction was assessed by checkerboard method. Sessile MIC (SMIC) of eugenol was equivalent to the planktonic MIC (PMIC) against C. albicans and S. mutans mixed biofilms. SMIC of fluconazole and azithromycin was increased upto 1000-folds over PMIC. Eradication of single or mixed biofilms was evident from the viability assay and SEM. At $1 \times$ MIC of eugenol, $\log _{10}$ CFU count of $C$. albicans cells were decreased from 6.3 to 4.2 and $3.8(p<0.05)$ in single and mixed biofilms, respectively. SEM studies revealed the eradication of $C$. albicans and S. mutans cells from glass surface at $800 \mu \mathrm{g} / \mathrm{mL}$ concentration of eugenol. Time dependent killing assay showed dose dependent effect of eugenol on pre-formed CAJ-01, CAJ-12 and S. mutans biofilm cells. Eugenol was highly synergistic with fluconazole $(\mathrm{FICl}=0.156)$ against $\mathrm{CAJ}-12$ single biofilms. However, the combination of eugenol and azithromycin showed maximum synergy $(\mathrm{FICl}=0.140)$ against pre-formed $\mathrm{C}$. albicans and S. mutans mixed biofilms. These findings highlighted the promising efficacy of eugenol in the eradication of biofilms of two oral pathogens (C. albicans and S. mutans) in vitro and could also be exploited in synergy with fluconazole and azithromycin in controlling oral infections.
\end{abstract}

Keywords: C. albicans, S. mutans, SMIC, PMIC, Biofilm eradication, FICl, Synergy

\section{Key points}

Mixed biofilm formation by the $C$. albicans and $S$. mutans, eradication of mixed biofilms by combine treatment of essential oil and antimicrobial drugs.
*Correspondence: humajafri01@gmail.com

1 Department of Agricultural Microbiology, Faculty of Agricultural Sciences, Aligarh Muslim University, Aligarh 202002, India

Full list of author information is available at the end of the article

\section{Introduction}

A variety of microbial species can colonize and adhere to oral cavity and cause number of infectious diseases including dental infections ( $\mathrm{Li}$ et al. 2000; Zhu et al. 2018). The members of oral microflora can form biofilms both on tissues or solid surface (dental implants). They interact among themselves and can develop mixed biofilms, and thereby, increasing the pathogenesis of disease. In industrialized countries, problem of dental caries has increased at an alarming rate in children and adults. About $60-80 \%$ of the children have been suffering from dental caries (Maripandi et al. 2011). Dental 
plaque is the most classic example of pathogenic biofilms (Vasudevan 2017). C. albicans can cause severe infection along with $S$. mutans in plaque biofilms in children with early childhood caries (Falsetta et al. 2014; Hwang et al. 2017). Approximately $25.5 \%$ of healthy individuals were encountered with both $C$. albicans and S. mutans in the denture plaque (Sztajer et al. 2014). The accumulation of $S$. mutans triggers the C. albicans biofilm formation under in vitro conditions (Barbosa et al. 2016) and may satisfy the requirement of metabolites or growth stimulating factors in mixed biofilm conditions. Streptococci also lead to the production of the cell wall anchored protein that assists in binding of Candida cells. C. albicans further utilizes the metabolized products and stimulate the production of ample amount of EPS which is important for aggregation and accumulation of $S$. mutans cells to develop mixed biofilms (Falsetta et al. 2014). Additionally, the increased population of Candida cells may also reduce the diversity of oral microbiome and substitute the microbial community with Strepoccocci (Kraneveld et al. 2012). The synergistic interaction between these pathogens helps in the establishment and pathogenicity in the oral environment (Morales and Hogan 2010).

Eradication of these pathogens is not always easy and successful because of their strong and compatible biofilm forming ability. It is evident from several studies that microorganisms in biofilm mode are less susceptible to the traditionally used antimicrobial drugs compared to the planktonic mode (Algburi et al. 2017). C. albicans has shown resistance against azole drugs and extended to echinocandins as well (Pristov and Ghannoum 2019). Also, the frequency of drug resistance in bacteria has been increased over the past decade. Various factors affect the susceptibility of the pathogens enfolded in a biofilm such as activation of biofilm phenotype, stress responses and decrease in the penetration of antimicrobial agents due to the EPS matrix (Mah Thien-Fah and O'Toole George 2001). Alternative strategies or development of more efficient antimicrobial agents showing activity against pathogenic biofilms are of great practical significance. The increasing incidence of multi drug resistance (MDR) in microbial pathogens and slow progress in novel anti-infective drug discovery has necessitated to scrutinize the traditionally used medicinal and herbal plants as an alternative drug (Khan et al. 2012; Pan et al. 2013; Yuan et al. 2016; Cheesman et al. 2017). Nowadays, there has been increasing interest in exploring plant materials as a source of new agents for the development of therapeutic compounds due to their diversity in bioactive compounds and safe use in traditional system of medicine. This is one of the potential approaches for the treatment of infections as they are safe for human and animal health. Essential oil compounds exhibit anti-biofilm properties, and these characteristics have been studied
(Jafri et al. 2019). Eugenol is a major active compound of $S$. aromaticum and with demonstrated antimicrobial action. The mechanism of action of eugenol is based on its ability to interfere cell wall and cytoplasmic membrane synthesis leading to leakage of intracellular material. Recently, eugenol has been reported to inhibit single and mixed biofilms of $C$. albicans and $S$. mutans biofilms (Jafri et al. 2019). Many authors have reported synergistic interaction between essential oil compounds with antimicrobial drugs as possible strategy to combat single and mixed biofilm infections (Khan et al. 2012; Borges et al. 2016; Fernandes et al. 2016; Roy et al. 2018). Therefore, we hypothesize that eugenol with multi-target activity might be useful in controlling mixed biofilms alone or in combination with fluconazole and or azithromycin. In this study, an in vitro eradication of the C. albicans and S. mutans mixed biofilm by eugenol alone and in combination with the antimicrobial drugs was studied using previously characterized strains of C. albicans and S. mutans MTCC497.

\section{Materials and methods \\ Microbial pathogens and microbiological media}

As previously identified and characterized, microbial strains of C. albicans (CAJ-01 and CAJ-12) and S. mutans MTCC497 were selected on the basis of strong biofilm forming ability (Jafri et al. 2019). The strains of C. albicans and $S$. mutans were maintained on Sabouraud dextrose agar (SDA) and nutrient agar (NA) slants at $4{ }^{\circ} \mathrm{C}$, respectively. Sabouraud dextrose broth/agar (SDB/SDA), nutrient agar, brain heart infusion broth (BHIB) and tryptic soy broth (TSB), were obtained from Hi-Media Laboratory, Mumbai, India. RPMI 1640 medium was purchased from Sigma, New Delhi, India. CAJ-01 strain was deposited to MTCC, Chandigarh, India with collection number MTCC, 13,013 .

\section{Antimicrobial drugs and eugenol}

Drug powders of fluconazole (Pfizer Co., India), amphotericin B (Hi-Media, India), azithromycin (Cipla, Mumbai, India) and chloramphenicol (Cipla, Mumbai, India) were used in this study. Stock solutions of antifungal drugs were prepared in dimethyl sulphoxide (DMSO) whereas antibacterial drugs in distilled water at a concentration of $25 \mathrm{mg} /$ $\mathrm{mL}$ and stored at $4{ }^{\circ} \mathrm{C}$ for not more than one week. Eugenol (99\% purity) was purchased from Hi-Media Laboratory, Mumbai, India. DMSO (1\%) was used to dilute eugenol.

\section{Determination of planktonic minimum inhibitory concentration (PMIC) of test agents against mixed $C$. albicans and S. mutans cells}

Susceptibility of planktonic cells of Candida and Streptococcus under mixed conditions was evaluated against the test agents using a modified method as described 
by $\mathrm{Li}$ et al. (2015). Briefly, $100 \mu \mathrm{L}$ of prepared twofold dilution of test agents (eugenol, fluconazole and azithromycin), $50 \mu \mathrm{L}$ of Candida $\left(2 \times 10^{3} \mathrm{CFU} / \mathrm{mL}\right)$ and $50 \mu \mathrm{L}$ of $S$. mutans inoculum $\left(2 \times 10^{5} \mathrm{CFU} / \mathrm{mL}\right)$ were added to the 96-well microtiter plate. Plates were incubated for $48 \mathrm{~h}$ at $37^{\circ} \mathrm{C}$. A well without any antimicrobial agent considered as negative control. MIC was calculated as the lowest concentration of antimicrobial agent that inhibited the visible growth of test organisms. Each experiment was conducted two times in triplicate.

\section{Determination of sessile minimum inhibitory concentration (SMIC) of test agents against mixed $C$. albicans and $S$. mutans cells}

Mixed biofilms of C. albicans (CAJ-01 and CAJ-12) and S. mutans MTCC497 was allowed to develop as described in our previous study (Jafri et al. 2019). Once the biofilms formed, non-adherent cells were washed thrice with sterile phosphate buffer saline (PBS). Next, $100 \mu \mathrm{L}$ of prepared two-fold serial dilutions of fluconazole, amphotericin B and eugenol in RPMI 1640 medium (for Candida biofilms), azithromycin and eugenol in BHI medium (for bacterial biofilms) and fluconazole, azithromycin and eugenol in TSB medium (for mixed biofilms) were added to each biofilm well of microtiter plates and incubated at $37^{\circ} \mathrm{C}$ for $48 \mathrm{~h}$. SMIC of the test compounds were assessed using XTT reduction assay. Sessile MIC (SMIC) of test agents was considered as the concentration eradicating $80 \%$ of pre-formed biofilm cells (Khan et al. 2012).

\section{Determination of viability of the single and mixed $C$. albicans and S. mutans biofilm cells}

Single and mixed biofilms of C. albicans (CAJ-01) and S. mutans MTCC497 was allowed to develop in 96-well plate (Jafri et al. 2019). Further, the viability of biofilm cells was determined by slightly modified method of Budzyńska et al. (2017). After incubation, biofilm mass were scraped off the walls of the wells by using a sterile scalpel and $100 \mu \mathrm{L}$ of PBS was added into the wells. The resulting suspension containing the biofilm cells was sonicated for 5 min to disturb the aggregates. After that cell suspension was serially diluted and spread on SDA/ NA plate. For mixed biofilms, cell suspension was spread on SDA plate supplemented with chloramphenicol (for C. albicans) and BHI agar plate supplemented with amphotericin B (for S. mutans). The resulting CFU count of biofim cells were calculated after $24 \mathrm{~h}$ incubation at $37^{\circ} \mathrm{C}$. Each assay was conducted two times in triplicate and mean $\log$ CFU was used to determine the viability of cells.
Scanning electron microscopy of pre-formed single and mixed biofilm cells treated with eugenol

Single and mixed biofilms were allowed to form using 24-well flat bottom culture plate with sterile coverslips using method as described by Harriott and Noverr (2009). Pre-formed single and mixed biofilms of CAJ01 and $S$. mutans MTCC497 cells were treated by adding $1000 \mu \mathrm{L}$ of prepared dilution of eugenol in the plate wells. The plates were incubated at $37^{\circ} \mathrm{C}$ for $48 \mathrm{~h}$. Glass coverslips containing biofilm cells were washed with PBS and fixed with $5 \%$ glutaraldehyde in cocodylate buffer in a graded concentration of ethanol $(25,50,75,95$ and $100 \%)$, immersed in hexamethyldisilazane and dried overnight at room temperature. The glass coverslips were then mounted on aluminium stubs with silver paint and sputter coated with gold using scanning electron microscope (JSM 6510, LV, JEOL, JAPAN). The micrographs were taken and processed.

\section{Kinetics of killing of pre-formed C. albicans and S. mutans biofilm cells}

To determine the potency of eugenol and antimicrobial drugs (fluconazole, amphotericin B and azithromycin), time kill assay of C. albicans and S. mutans biofilm cells were performed using method as described and modified by Khan and Ahmad (2012) and Yadav et al. (2015) respectively. Pre-formed Candida and S. mutans biofilm cells were treated with $2 \times$ MIC of eugenol and antimicrobial drugs. Samples of Candida and S. mutans biofilms were removed immediately, serially diluted and plated on SDA and NA plate respectively. For Candida biofilms, the treated biofilm cells were collected after 2 , $4,8,12,24$ and $48 \mathrm{~h}$ of incubation whereas treated bacterial biofilms cells were collected after incubation of 0.5 , $1,1.5,3,6,12,24$ and $48 \mathrm{~h}$. After completion of incubation period, the wells were washed to remove loosely adhered cells and biofilm mass was scraped off the well using a sterile scalpel. The samples were diluted in saline solution and plated on agar plates. Biofilm wells without any treatment served as a control. The mean CFU count was used to determine the viable cells. All the experiments were performed in triplicates in three independent experiments.

\section{In vitro studies of synergy between eugenol and antimicrobial drugs against single and mixed biofilms of C. albicans and S. mutans}

The combine effect of eugenol and antimicrobial drugs (fluconazole, amphotericin B and azithromycin) on single and mixed biofilm cells were determined by checkerboard microtiter assay as described by Vitale et al. 2005 with little modifications, Briefly, single and mixed 
biofilms of $C$. albicans and $S$. mutans were allowed to form in 96-well microtiter plate by using the method as described in previous section. Then, pre-formed single and mixed $C$. albicans (CAJ-01 and CAJ-12) and $S$. mutans MTCC497 biofilm cells were treated with various combinations of test agents (eugenol and antimicrobial drugs) by adding $50 \mu \mathrm{L}$ of each prepared dilution of eugenol and drugs in the vertical and horizontal direction of the plate respectively. Further, the plates were incubated at $37^{\circ} \mathrm{C}$ for $48 \mathrm{~h}$. The extent of synergy was determined in terms of FICI index. An FICI index (FICI) was calculated by adding both FICIs. The FICI result was interpreted as: synergistic: $\mathrm{FICI} \leq 0.5$, no interaction or indifferent $>0.5-$ 4.0, antagonistic $>4.0$ (Khan and Ahmad 2012).

\section{Results}

Eugenol showed no increase in SMIC against the mixed biofilm of C. albicans plus S. mutans MTCC497. Antimicrobial drugs (fluconazole and azithromycin) showed up to 1000-fold increase in SMIC compared to the PMIC against the test microbial strains combination as revealed from Table 1.

Further, viability of $C$. albicans and $S$. mutans preformed single and mixed biofilm cells was recorded after challenging with the different concentrations of eugenol $(0.5 \times \mathrm{MIC}, 1 \times \mathrm{MIC}$ and $2 \times \mathrm{MIC})$ and as depicted in Fig. 1. The data revealed the marked reduction in $\log _{10}$ CFU count of $C$. albicans and $S$. mutans in single biofilms with the increasing concentration of eugenol. The eradication of single and mixed biofilms was recorded at $1 \times \mathrm{MIC}$ and $2 \times \mathrm{MIC}$, which was equivalent to the SMIC of the eugenol. Remarkable reduction in Candida and S. mutans CFU count was observed at $2 \times$ MIC of eugenol in single biofilms. $\log _{10}$ CFU count of $C$. albicans cells was reduced from 6.3 to 4.2 and 3.8 $(\mathrm{p}<0.05)$ in single and mixed biofilms, respectively. There were remarkable reduction in CFU count of $C$. albicans cells compared to the $S$. mutans cells at $1 \times$ MIC of eugenol in mixed conditions. Chlorhexidine digluconate (CHX) was used as a positive control $(200 \mu \mathrm{g} / \mathrm{mL})$ for biofilm eradication which was a recorded as $50 \times \mathrm{MIC}$ of CHX against CAJ-01 (Jafri et al. 2019). The activity of eugenol was found comparable to positive control.

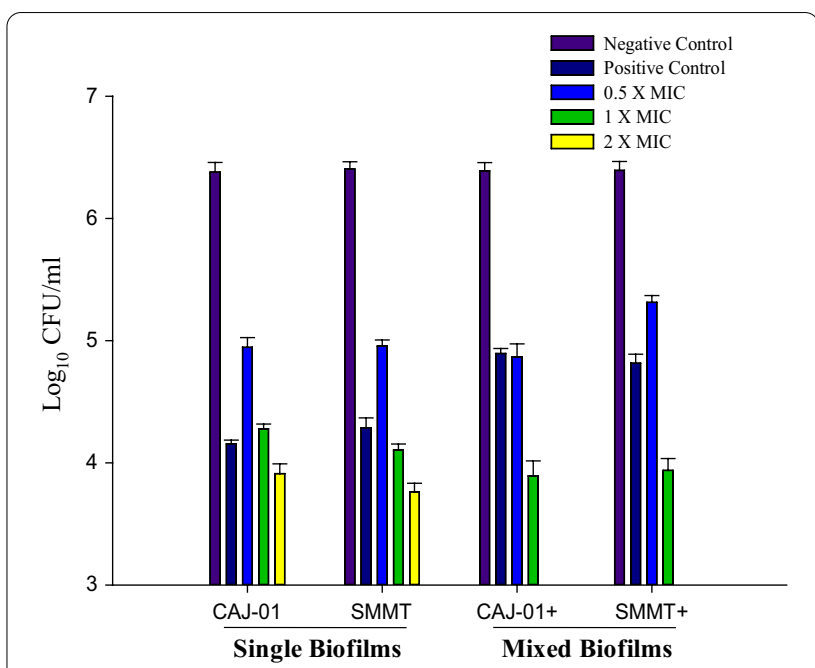

Fig. 1 Viability of pre-formed CAJ-01 and S. mutans MTCC497 single and mixed biofilm cells on exposure with different concentration of the eugenol. Negative Control: Untreated single and mixed biofilm cells. Positive Control: CHX (200 $\mu \mathrm{g} / \mathrm{mL})$ treated cells, CAJ-01+: Viable cells of CAJ-01 in mixed biofilms, SMMT+: Viable cells of S. mutans MTCC497 in mixed biofilms

Eradication of pre-formed single and mixed biofilms cells was also observed at higher concentration of the test agents $(2 \times \mathrm{MIC})$ under scanning electron microscope (Fig. 2b). SEM images clearly depicted distortion in $C$. albicans biofilm architecture at $2 \times$ MIC of eugenol compared to the untreated control cells. Similarly, pre-formed S. mutans biofilms was eradicated at $2 \times$ MIC of the test agents. S. mutans single species biofilm cells showed abnormal cell structure, lesser number of cell aggregation and removal of EPS matrix (Fig. 2d). Damaged cell morphology, shrinkage of the yeast cells and eradication of $C$. albicans and $S$. mutans cells were also observed in the $C$. albicans (CAJ-01) plus S. mutans MTCC497 mixed biofilms after treatment with eugenol (Fig. 2f).

Dose dependent killing of pre-formed biofilms of C. albicans (CAJ-01 and CAJ-12) and S. mutans MTCC497 were observed at $2 \times$ SMIC of eugenol and antimicrobial drugs (fluconazole, amphotericin $\mathrm{B}$ and azithromycin). Treatment of pre-formed biofilms with $2 \times$ SMIC of eugenol showed strong fungicidal effect on

Table 1 PMIC and SMIC of eugenol and antimicrobial drugs against the mixed cells of C. albicans and S. mutans MTCC497

\begin{tabular}{|c|c|c|c|c|c|c|}
\hline \multirow[t]{2}{*}{ Strains } & \multicolumn{2}{|c|}{ Eugenol } & \multirow{2}{*}{$\begin{array}{l}\text { Fluconazole } \\
\text { PMIC }\end{array}$} & \multirow[b]{2}{*}{ SMIC } & \multirow{2}{*}{$\begin{array}{l}\text { Azithromycin } \\
\text { PMIC }\end{array}$} & \multirow[b]{2}{*}{ SMIC } \\
\hline & PMIC & SMIC & & & & \\
\hline CAJ-01 plus S. mutans MTCC497 & 800 & 800 & 8 & 1024 & 128 & 1024 \\
\hline CAJ-12 plus S. mutans MTCC497 & 200 & 200 & 1024 & 2048 & 128 & 1024 \\
\hline
\end{tabular}

Values of PMIC and SMIC are given in $\mu \mathrm{g} / \mathrm{mL}$ 

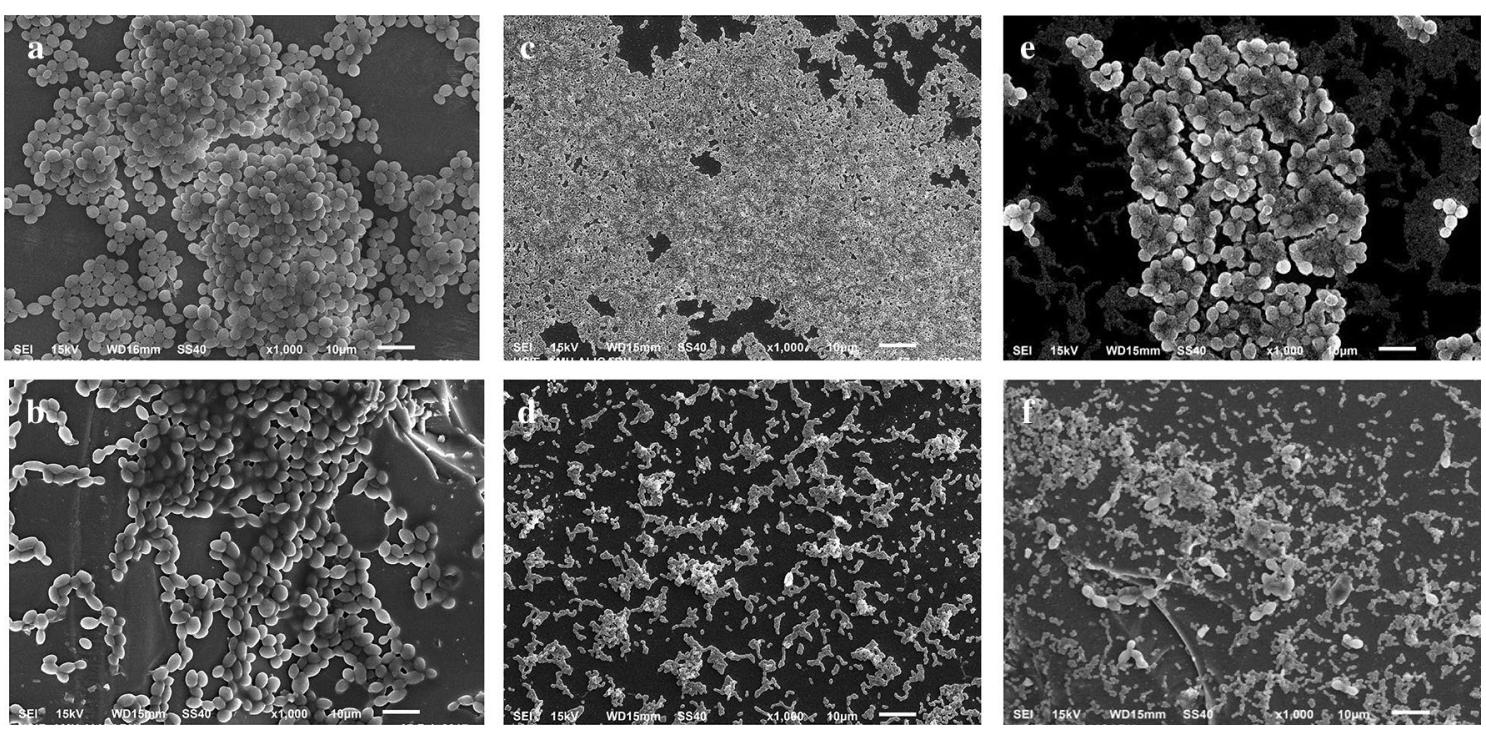

Fig. 2 Eradication of pre-formed C. albicans (CAJ-01) and S. mutans MTCC497 single and mixed biofilms by the treatment of eugenol. a CAJ-01 untreated biofilms, b Treated with eugenol at $400 \mu \mathrm{g} / \mathrm{mL}$, c S. mutans MTCC497 untreated biofilm cells, d S. mutans MTCC497 biofilm cells treated with eugenol at $400 \mu \mathrm{g} / \mathrm{mL}$, e Untreated CAJ-01 and S. mutans MTCC497 mixed biofilm cells (Jafri et al. 2019), f. CAJ-01 and S. mutans MTCC497 biofilm cells treated with eugenol at $800 \mu \mathrm{g} / \mathrm{mL}$

C. albicans biofilms. Noticeable reduction in $\log _{10} \mathrm{CFU}$ count of C. albicans biofilm cells was observed within $12 \mathrm{~h}$ of treatment of eugenol. Whereas amphotericin $\mathrm{B}$ and fluconazole could not produce effective killing effect even upto $48 \mathrm{~h}$ of treatment (Fig. 3a, b).

Similarly, dose dependent killing effect was observed within $180 \mathrm{~min}$ after exposure with eugenol on preformed S. mutans MTCC497 biofilms. However, the effective biofilm eradication activity of azithromycin was noticed after $24 \mathrm{~h}$ of treatment on the pre-formed bacterial biofilms (Fig. 3c).

The interaction between euegnol and antimicrobial drugs (fluconazole, amphotericin B and azithromycin) was studied against the single and mixed biofilms and as depicted in Table 2. Synergy was observed between the eugenol and fluconazole against the CAJ-01 and CAJ12 pre-formed biofilms with FICI value ranging from 0.156 to 0.250 . However, indifferent interaction was noticed between eugenol and amphotericin $\mathrm{B}$ against the pre-formed $C$. albicans biofilm cells ( $\mathrm{FICI}=0.625)$. Similarly, synergistic interaction between eugenol and azithromycin against pre-formed S. mutans MTCC497 biofilms was recorded. Synergy was also noticed between eugenol and antimicrobial drugs (fluconazole and azithromycin) against the pre-formed C. albicans and S. mutans mixed biofilms. However, eugenol showed maximum synergy with azithromycin against C. albicans plus S. mutans MTCC497 mixed biofilms and FICI value was found 0.140. SMIC of azithromycin was reduced upto 8-folds against S. mutans MTCC497 in mixed biofilms.

\section{Discussion}

The inhibitory potential of antimicrobial agents was conducted on single biofilms and little work is being done so far under mixed condition. C. albicans and S. mutans are very deleterious in mixed biofilms. The interaction between these two pathogens produces resistant and recalcitrant infections in oral environment, which may further enhance complications in the treatment of oral infections (Peters et al. 2012; Gabrilska and Rumbaugh 2015). Therefore, the knowledge of mixed biofilms and their disruption strategy is utmost important to develop therapeutically useful approach. Due to increase in microbial resistance to existing antimicrobial drugs and decline in the formulation of new antimicrobial drugs, there has been witnessed an increased global interest in anti-infective natural products derived from medicinal plants. Various plant derived products (essential oils and phytocompounds) have so far been screened across the globe for their anti-biofilm activities. However, little attention was given to explore their therapeutic potential and its synergy with antimicrobial drugs against mixed biofilms.

Eugenol has potential to eradicate the single and mixed biofilms which are less susceptible to antimicrobial drug therapy. Emergence of phytocompounds resistant microbial strains is also not reported probably due to 

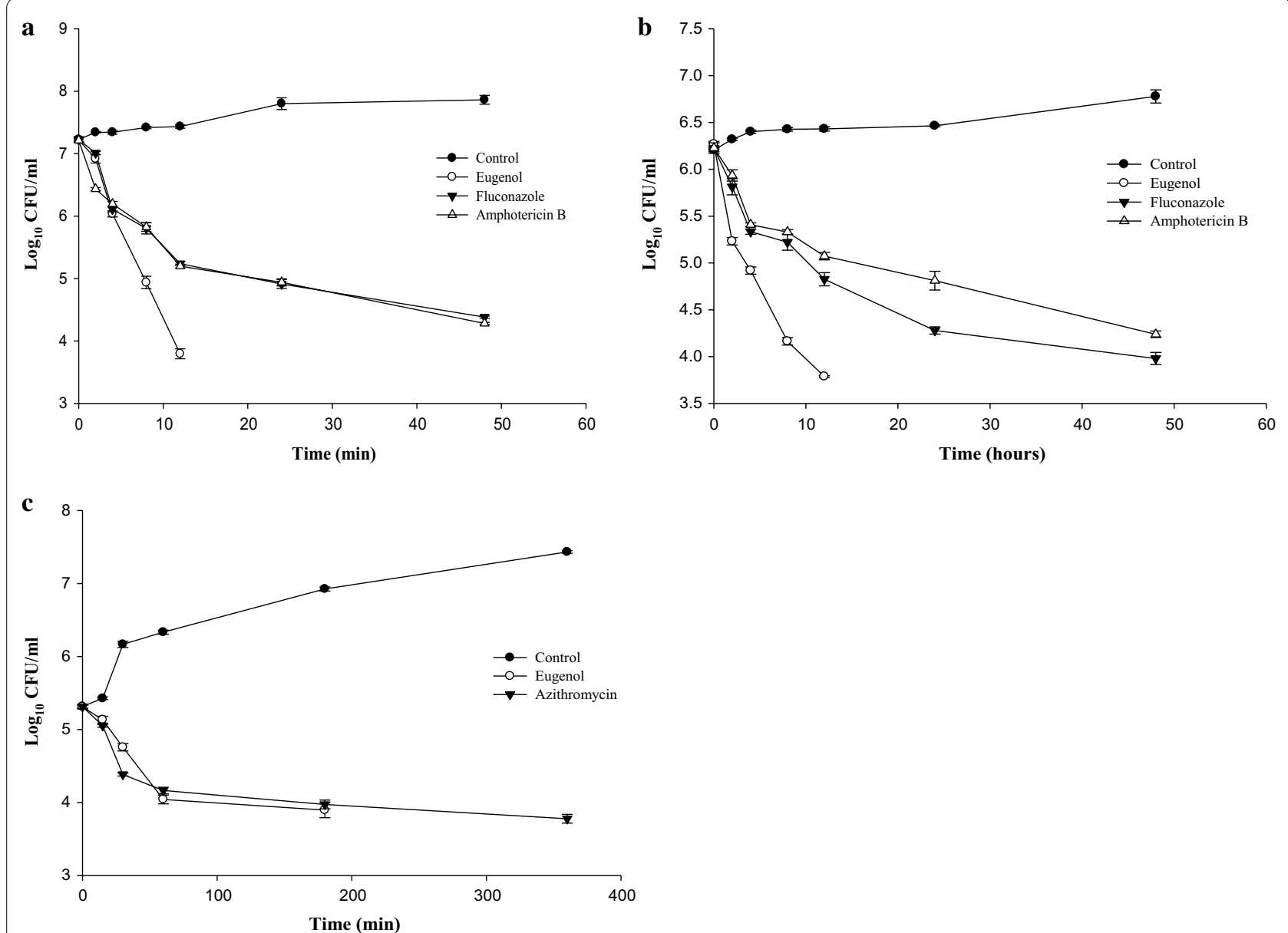

Fig. 3 Time kill curves for eugenol and antimicrobial drugs against pre-formed C. albicans (CAJ-01 and CAJ-12) and S. mutans MTCC497 biofilms. a CAJ-01, b CAJ-12, c S. mutans MTCC497

its multiple mode of action (Kavanaugh et al. 2012). The antimicrobial effect of eugenol has made them very effective alternative therapeutic agents.

In the present study, an effort has been made to evaluate eugenol potential to eradicate single and mixed biofilms alone and also in combination with known antimicrobial drugs against characterized C. albicans (CAJ01 and CAJ-12) and S. mutans MTCC497 strains. This is a probably first attempt in this direction.

In this study, eugenol eradicates the mixed sessile cells of C. albicans and S. mutans. Interestingly, SMIC of eugenol is equivalent to PMIC of mixed C. albicans and $S$. mutans cells. This implies that eugenol under study are equally effective against both planktonic and sessile cells of C. albicans and S. mutans. Mixed biofilm cells of $C$. albicans plus $S$. mutans were sensitive to fluconazole in planktonic condition. In contrast, sessile cells were highly resistant to fluconazole in mixed condition. Apparently, SMIC of antimicrobial drugs (fluconazole and azithromycin) was increased upto1000-folds against C. albicans and $S$. mutans cells in the mixed bioiflms. Due to the limited penetration of antimicrobial drugs in these conditions, there is a need to increase the dose of the drugs which may further cause toxicological risks. It is also evident that eugenol was more effective on mixed species biofilm as compared to the single biofilm cells due to the increased susceptibility of mixed cells to eugenol (Jafri et al. 2019). Similar findings were also reported by the Fernandes et al. (2016). They studied the effect of farnesol on the pre-formed single and mixed biofilms of C. albicans and $S$. mutans and observed that farnesol was more effective on the mixed species biofilms compared to the single species biofilms.

The concentration dependent eradication of preformed single and mixed biofilms is also demonstrated by the viability assay. The findings of this study have revealed eradication of Candida and bacterial single biofilm cells occurred at higher MIC of eugenol. However, mixed biofilm cells were eradicated at MIC value of eugenol. This highlighted that there were lesser increase in tolerance of 
Table 2 Combinational effects of eugenol and antimicrobial drugs on pre-formed C. albicans and S. mutans MTCC497 single and mixed biofilms

\begin{tabular}{|c|c|c|c|c|}
\hline \multirow{2}{*}{$\frac{\text { Test strains }}{1 . \text { CAJ-01 }}$} & \multicolumn{4}{|c|}{ Test combinations (concentration) } \\
\hline & EUG/FLZ ( $\mu \mathrm{g} / \mathrm{mL})$ & & EUG/AMB $(\mu \mathrm{g} / \mathrm{mL})$ & \\
\hline & EUG & FLZ & EUG & $\mathrm{AMB}$ \\
\hline Alone MIC & 400 & 512 & 400 & 256 \\
\hline Combination MIC & 50 & 64 & 100 & 128 \\
\hline $\mathrm{FICl}$ & 0.250 & & 0.625 & \\
\hline Type of interaction & Synergy & & Indifferent & \\
\hline \multirow[t]{2}{*}{ 2. CAJ-12 } & EUG/FLZ ( $\mu \mathrm{g} / \mathrm{mL})$ & & EUG/AMB $(\mu \mathrm{g} / \mathrm{mL})$ & \\
\hline & EUG & FLZ & EUG & $\mathrm{AMB}$ \\
\hline Alone MIC & 200 & 1024 & 200 & 32 \\
\hline Combination MIC & 6.25 & 128 & 25 & 16 \\
\hline $\mathrm{FICl}$ & 0.156 & & 0.625 & \\
\hline Type of interaction & Synergy & & Indifferent & \\
\hline \multirow[t]{2}{*}{ 3. S. mutans MTCC497 } & EUG/AZI ( $\mu \mathrm{g} / \mathrm{mL})$ & & & \\
\hline & EUG & AZI & & \\
\hline Alone MIC & 200 & 512 & & \\
\hline Combination MIC & 12.5 & 64 & & \\
\hline $\mathrm{FICl}$ & 0.187 & & & \\
\hline Type of interaction & Synergy & & & \\
\hline \multirow[t]{2}{*}{ 4. CAJ-01 plus S. mutans MTCC497 } & EUG/FLZ ( $\mu \mathrm{g} / \mathrm{mL})$ & & EUG/AZI ( $\mu \mathrm{g} / \mathrm{mL})$ & \\
\hline & EUG & FLZ & EUG & AZI \\
\hline Alone MIC & 800 & 1024 & 800 & 1024 \\
\hline Combination MIC & 25 & 128 & 12.5 & 128 \\
\hline $\mathrm{FICl}$ & 0.156 & & 0.140 & \\
\hline Type of interaction & Synergy & & Synergy & \\
\hline \multirow[t]{2}{*}{ 5. CAJ-12 plus S. mutans MTCC497 } & EUG/FLZ ( $\mu \mathrm{g} / \mathrm{mL})$ & & EUG/AZI ( $\mu \mathrm{g} / \mathrm{mL})$ & \\
\hline & EUG & $\mathrm{FLZ}$ & EUG & AZI \\
\hline Alone MIC & 200 & 2048 & 200 & 1024 \\
\hline Combination MIC & 12.5 & 256 & 3.12 & 128 \\
\hline $\mathrm{FICl}$ & 0.187 & & 0.140 & \\
\hline Type of interaction & Synergy & & Synergy & \\
\hline
\end{tabular}

EUG eugenol, FLC fluconaole, $A M B$ amphotericin $B, A Z l$ azithjromycin

the eugenol towards the mixed bioflm cells compared to single biofilm cells.

Furthermore, efficacy of eugenol is demonstrated in terms of the time dependent killing of $C$. albicans and $S$. mutans matured biofilms. Eugenol showed efficacy within $12 \mathrm{~h}$ whereas antimicrobial drugs were ineffective even after $48 \mathrm{~h}$ of treatment against biofilm cells. Therefore, eugenol is considered as more cidal and potential antibiofilm agent compared to these antimicrobial drugs. Further, the eradication of pre-formed single and mixed biofilms at higher concentration of eugenol was also confirmed by scanning electron microscopy. Microscopy revealed distorted cell structure, reduced matrix production and eradication of single and mixed biofilm cells of C. albicans and S. mutans cells compared to untreated control at higher concentration of eugenol. Eradication of Candida biofilms in the presence of essential oils namely cinnnamaldehyde, linalool, Melaleuca alternifolia, Mentha longifolia is also reported by many workers de Campos Rasteiro et al. 2014; Serra et al. 2018; Tutar 2018).

In the light of synergistic approach, it is expected that synergy between eugenol and antimicrobial drugs against C. albicans and $S$. mutans could provide a new formulation for disease treatment (Nascimento et al. 2008; de Castro et al. 2015; Barbieri et al. 2017). Therefore, exploring nature of interaction between antimicrobial drugs with test compounds is pre-requisite to develop effective combinations. The nature of interactions can be indifferent, additive, synergistic and antagonistic. Synergy occurs when the combine effect of two test agents is greater 
than the effect of individual test agents (Cheesman et al. 2017). The mechanism of action in synergistic interaction may comprises of one or more actions like blocking of receptor, modification of the target site, degradation by enzymes, modification of the drugs, and accumulation of the antibiotics inside the microbes due to inhibition of outer membrane permeability (Bhardwaj et al. 2016; Stefanović, 2018; Ayaz et al. 2019).

In sessile mode of growth, eugenol has synergy with antimicrobial drugs (fluconazole and azithromycin) against the strains of $C$. albicans and S. mutans MTCC497. The synergistic interaction between eugenol and azithromycin has not been reported so far against S. mutans. Azithromycin inhibits the protein synthesis, quorum sensing and also biofilm formation (Parnham et al. 2014). Antibiotics in association with essential oils compounds can target multiple sites simultaneously and may reduce the drug related toxicity.

The FICI index study revealed the synergistic interaction between the eugenol and antimicrobial drugs to control the C. albicans and S. mutans single biofilms infections. This interaction studies were further exploited against the $C$. albicans and $S$. mutans mixed biofilms. This is a first report on the interaction study of eugenol with antimicrobial drugs against $C$. albicans and $S$. mutans mixed biofilms. In this study, eugenol showed maximum synergy with azithromycin against $C$. albicans and S. mutans MTCC497 in mixed biofilms. The SMIC of antimicrobial drugs were reduced upto 8-folds against the Candida and bacteria in mixed biofilms. The combination therapy has several advantages that may help to overcome the limitations of monotherapy for the treatment of mixed biofilms. The essential oil compound is equally effective against the bacterial and fungal cell which is not possible with antifungal and antibacterial drugs. The antifungal and antibacterial drugs will merely target the Candida and bacterial cells respectively. It is expected that eugenol perturbs the cell membrane integrity and allows the entry of drug into the microbial cell. This makes the antimicrobial drug available to the target site and resulted in improved efficacy.

Interestingly, the combination of antimicrobial drugs and eugenol could offers several advantages like enhanced potency, reduced dose of drugs, minimized toxicity which ultimately helps to inhibit or eradicate biofilms and overcome antimicrobial drug resistance (Chaouhan et al. 2017).

Thus, dose dependent killing effect of the eugenol-antimicrobial drug treatment suggests that these combinations could be subjected to treat the oral mixed biofilm infections.Further, the eugenol-drug combinations may be extended to different oral pathogens forming mixed pathogenic biofilms. Synergistic interaction between eugenol and antimicrobial drugs in planktonic and sessile mode needs to be evaluated on suitable animal model to assess its therapeutic efficacy. Further, based on the interaction of eugenol with antifungal and antibacterial drugs, a broad spectrum formulation may be standardized for topical application after assessing the toxicity issue if any.

Synergy of eugenol with azithromycin and fluconazole highlights the promising potential of phytocompounds to be used in combinational anti-infective therapy to combat single and mixed C. albicans and S. mutans biofilm associated infections. Further, in vivo efficacy is required for clinical application.

\section{Acknowledgements}

The authors are thankful to the University Sophisticated Instruments Facility (USIF) at Aligarh Muslim University. $\mathrm{HJ}$ is also grateful for providing financial support in the form of Non-Net Research Fellowship by University Grant Commission, New Delhi.

\section{Authors' contribution}

$\mathrm{HJ}$ and IA conceived and designed manuscript. HJ performed experiments and wrote manuscript. GB provided clinical strains of C. albicans. MSAK, HHA and ASA analyzed data. MSAK contributed new method. All authors read and approved the final manuscript.

\section{Competing interests}

The authors declare that they have no competing interests

\section{Author details}

${ }^{1}$ Department of Agricultural Microbiology, Faculty of Agricultural Sciences, Aligarh Muslim University, Aligarh 202002, India. ${ }^{2}$ Department of Microbiology, King George Medical University, Lucknow 226020, India. ${ }^{3}$ Department of Basic Sciences, Deanship of Preparatory Year and Supporting Studies, Imam Abdulrahman Bin Faisal University, P.O. Box 1982, Dammam 34212, Saudi Arabia. ${ }^{4}$ Department of Biology, Faculty of Applied Science, Umm Al-Qura University, Makkah, Kingdom of Saudi Arabia.

Received: 21 June 2020 Accepted: 7 October 2020

Published online: 19 October 2020

\section{References}

Algburi A, Comito N, Kashtanov D, Dicks LM, Chikindas ML (2017) Control of biofilm formation: antibiotics and beyond. Appl Environ Microbiol 83(3):e02508-e02516

Ayaz M, Ullah F, Sadiq A, Ullah F, Ovais M, Ahmed J, Devkota HP (2019) Synergistic interactions of phytochemicals with antimicrobial agents: potential strategy to counteract drug resistance. Chem-Biol Interact 10:12

Barbieri R, Coppo E, Marchese A, Daglia M, Sobarzo-Sánchez E, Nabavi SF, Nabavi SM (2017) Phytochemicals for human disease: an update on plant-derived compounds antibacterial activity. Microbiol Res 196:44-68

Barbosa JO, Rossoni RD, Vilela SF, De Alvarenga JA, dos Santos Velloso M, de AzevedoPrata MC, Jorge AO, Junqueira JC (2016) Streptococcus mutans can modulate biofilm formation and attenuate the virulence of Candida albicans. PLoS One 11(3):e0150457

Bhardwaj M, Singh BR, Sinha DK, Kumar V, Vadhana P, Vinodhkumar OR, Singh VS, Nirupama KR, Shree P, Saraf A (2016) Potential of herbal drug and antibiotic combination therapy: A new approach to treat multidrug resistant bacteria. Pharm Anal Acta. 7(11):523

Borges A, Abreu A, Dias C, Saavedra M, Borges F, Simões M (2016) New perspectives on the use of phytochemicals as an emergent strategy to control bacterial infections including biofilms. Molecules 21(7):877

Budzyńska A, Różalska S, Sadowska B, Różalska B (2017) Candida albicans/ Staphylococcus aureus Dual-Species Biofilm as a Target for the Combination of Essential Oils and Fluconazole or Mupirocin. Mycopathologia 182(11-12):989-995 
Cheesman MJ, llanko A, Blonk B, Cock IE (2017) Developing new antimicrobial therapies: are synergistic combinations of plant extracts/compounds with conventional antibiotics the solution? Pharmacogn Rev 11(22):57

Chouhan S, Sharma K, Guleria S (2017) Antimicrobial activity of some essential oils-present status and future perspectives. Medicines 4(3):58

de Campos Rasteiro VM, da Costa AC, Araújo CF, De Barros PP, Rossoni RD, Anbinder AL, Jorge AO, Junqueira JC (2014) Essential oil of Melaleucaalternifolia for the treatment of oral candidiasis induced in an immunosuppressed mouse model. BMC Complem Altern M 14(1):489

de Castro RD, de Souza TMPA, Bezerra LMD, Ferreira GLS, Costa EMMDeB, Cavalcanti AL (2015) Antifungal activity and mode of action of thymol and its synergism with nystatin against Candida species involved with infections in the oral cavity: an in vitro study. BMC Complem Altern M 15:417

Falsetta ML, Koo H (2014) Beyond mucosal infection: a role for C. albicansStreptococcal interactions in the pathogenesis of dental caries. Curr Oral Health Rep 1(1):86-93

Fernandes RA, Monteiro DR, Arias LS, Fernandes GL, Delbem AC, Barbosa DB (2016) Biofilm formation by Candida albicans and Streptococcus mutans in the presence of farnesol: a quantitative evaluation. Biofouling 32(3):329-338

Gabrilska RA, Rumbaugh KP (2015) Biofilm models of polymicrobial infection. Future Microbiol 10(12):1997-2015

Harriott MM, Noverr MC (2009) Candida albicans and Staphylococcus aureus form polymicrobial biofilms: effects on antimicrobial resistance. Antimicrob Agents Chemother 53(9):3914-3922

Hwang G, Liu Y, Kim D, Li Y, Krysan DJ, Koo H (2017) Candida albicansmannans mediate Streptococcus mutansexoenzymeGtfB binding to modulate cross-kingdom biofilm development in vivo. Plos Pathog 13(6):e1006407

Jafri H, Khan MS, Ahmad I (2019) In vitro efficacy of eugenol in inhibiting single and mixed-biofilms of drug-resistant strains of Candida albicans and Streptococcus mutans. Phytomed 15:206-213

Kavanaugh NL, Ribbeck K (2012) Selected antimicrobial essential oils eradicate Pseudomonas spp. and Staphylococcus aureus biofilms. Appl Environ Microbiol 78(11):4057-4061

Khan MS, Ahmad I (2012) Antibiofilm activity of certain phytocompounds and their synergy with fluconazole against Candida albicans biofilms. J Antimicrob Chemother 67(3):618-621

Khan MS, Malik A, Ahmad I (2012) Anti-candidal activity of essential oils alone and in combination with amphotericin B or fluconazole against multidrug resistant isolates of Candida albicans. Medicine 50(1):33-42

Kraneveld EA, Buijs MJ, Bonder MJ, Visser M, Keijser BJ, Crielaard W, Zaura E (2012) The relation between oral Candida load and bacterial microbiome profiles in Dutch older adults. PLOS ONE 7:8

Li H, Zhang C, Liu P, Liu W, Gao Y, Sun S (2015) In vitro interactions between fluconazole and minocycline against mixed cultures of Candida albicans and Staphylococcus aureus. J Microbiol Immunol Infect 48(6):655-661

Li X, Kolltveit KM, Tronstad L, Olsen I (2000) Systemic diseases caused by oral infection. Clin Microbiol Rev 13(4):547-558

Mah Thien-Fah C, O'Toole George A (2001) Mechanisms of biofilm resistance to antimicrobial agents. Trends Microbiol 9(1):34-39

Maripandi A, Kumar A, Al Salamah AA (2011) Prevalence of dental caries bacterial pathogens and evaluation of inhibitory concentration effect on different tooth pastes against Streptococcus spp. Afr J Microbiol Res 5(14):1778-1783

Morales DK, Hogan DA (2010) Candida albicans interactions with bacteria in the context of human health and disease. Plos Pathog 6(4):e1000886

Nascimento JG, Guerreiro-Pereira MC, Costa SF, José C, Santos MA (2008) Nisintriggered activity of Lys44, the secreted endolysin from Oenococcus oeni Phage fOg44. J Bacteriol 190(1):457-461

Pan SY, Zhou SF, Gao SH, Yu ZL, Zhang SF, Tang MK, Sun JN, Ma DL, Han YF, Fong WF, Ko KM (2013) New perspectives on how to discover drugs from herbal medicines: CAM's outstanding contribution to modern therapeutics. Evid Based Complement Alternat Med. 2013:12

Parnham MJ, Haber VE, Giamarellos-Bourboulis EJ, Perletti G, Verleden GM, Vos R (2014) Azithromycin: mechanisms of action and their relevance for clinical applications. Pharmacol Ther 143(2):225-245

Peters BM, Jabra-Rizk MA, O'May GA, Costerton JW, Shirtliff ME (2012) Polymicrobial interactions: impact on pathogenesis and human disease. Clin Microbiol Rev 25(1):193-213

Pristov KE, Ghannoum MA (2019) Resistance of Candida to azoles and echinocandins worldwide. Clin Microbiol Infect 25(7):792-798

Roy R, Tiwari M, Donelli G, Tiwari V (2018) Strategies for combating bacterial biofilms: A focus on anti-biofilm agents and their mechanisms of action. Virulence 9(1):522-554

Serra E, Hidalgo-Bastida L, Verran J, Williams D, Malic S (2018) Antifungal activity of commercial essential oils and biocides against Candida albicans. Pathogens 7(1):15

Stefanović OD (2018) Synergistic activity of antibiotics and bioactive plant extracts: a study against Gram-positive and Gram-negative bacteria. Bact Pathogen Antibact Control 2:3

Sztajer H, Szafranski SP, Tomasch J, Reck M, Nimtz M, Rohde M, Wagner-Döbler I (2014) Cross-feeding and interkingdom communication in dualspecies biofilms of Streptococcus mutans and Candida albicans. ISME J $8(11): 2256-2271$

Tutar U (2018) Evaluation of anti-biofilm and antifungal activities of Mentha longifolia essential oil against clinical isolates of Candida albicans. Wjpmr. $4(7): 150-154$

Vasudevan R (2017) Dental Plaques: Microbial community of the oral cavity. J Microbiol Exp 4(1):00100

Vitale RG, Afeltra J, Dannaoui E (2005) Antifungal combinations (Methods in molecular medicine). In: Ernst EJ, Rogers PD (eds) Antifungal Agents: Methods and Protocols. Humana Press Inc, Totowa, pp 143-152

Yadav MK, Chae SW, Im GJ, Chung JW, Song JJ (2015) Eugenol: a phytocompound effective against methicillin-resistant and methicillin-sensitive Staphylococcus aureus clinical strain biofilms. PLoS ONE 10(3):e0119564

Yuan H, Ma Q, Ye L, Piao G (2016) The traditional medicine and modern medicine from natural products. Molecules 21(5):559

Zhu B, Macleod LC, Kitten T, Xu P (2018) Streptococcus sanguinis biofilm formation \& interaction with oral pathogens. Future Microbiol 13(8):915-932

\section{Publisher's Note}

Springer Nature remains neutral with regard to jurisdictional claims in published maps and institutional affiliations.

\section{Submit your manuscript to a SpringerOpen ${ }^{\odot}$ journal and benefit from:}

- Convenient online submission

- Rigorous peer review

- Open access: articles freely available online

- High visibility within the field

- Retaining the copyright to your article

Submit your next manuscript at $\boldsymbol{\nabla}$ springeropen.com 